\title{
An Analysis of Meaning Negotiation Strategies Used in Conversation by Undergraduate EFL Students
}

\author{
Rudi Hartono ${ }^{1}$, Diemroh Ihsan ${ }^{2}$ \\ Indo Global Mandiri University Palembang, Indonesia \\ Sriwijaya University Palembang, Indonesia \\ rudihartonojr@yahoo.com
}

\begin{abstract}
Negotiation of meaning occurs in the interactions as a communication strategy to make meaning comprehensible. In a conversation, speakers and interlocutors may employ negotiation of meaning strategy to achieve mutual understanding. Negotiation of meaning is important in language acquisition and second or foreign language learning. With the use of negotiation of meaning, speakers and interlocutors can avoid misunderstanding and communication breakdowns. This qualitative study examined the ways in which learners of English employed negotiation of meaning strategies in conversation performed by six undergraduate EFL students. The data were collected through the participants' performance in an information gap activity, Spot the Difference task and analyzed using conversation analysis. The results revealed that frequently used negotiation of meaning strategies (confirmation checks, repetitions, and self-corrections) were used to help their interlocutors understand and comprehend meaning. Furthermore, this study revealed that the information gap activity provided opportunity for the participants to negotiate meaning as it required them to exchange information and compare the similarities and differences of their pictures. Finally, the study suggests that there is a need to examine the impact of negotiation of meaning in classroom interaction and the extent to which negotiation of meaning contributes to second or foreign language learning.
\end{abstract}

Key words: communication strategy, negotiation of meaning, EFL learners

\section{INTRODUCTION}

Negotiation of meaning in L2 poses a challenge to the curriculum planners and teachers to provide strategy training in negotiation of meaning. There is a need to examine the impact of negotiation for meaning on classroom interaction. There should be investigations on the extent to which negotiation of meaning training contribute to L2 learning. Lengluan (2008) argues that negotiation of meaning can be promoted in an English classroom, when the teacher constructs an interactive learning environment with appropriate communication tasks.

In conversation, a speaker may employ another communication strategy to communicate effectively using negotiation of meaning. According to Pica (1987), negotiation of meaning refers to "activity that occurs when a listener signals to the speaker that the speaker's message is not clear and the speaker and listener work linguistically to resolve this impasse" (p. 200). Negotiation is employed by speakers in order to achieve successful communication and to accomplish various functions of language. Richards and Schmidt (2002) argue that "negotiation of meaning happens when interlocutors attempt to overcome problems in conveying their meaning, resulting in both additional input and useful feedback on the learner's own production" ( $p$. 264). Luciana's (2005) study revealed that negotiation of meaning provided a potentially rich forum for language development and promoted students' active involvement.

A number of L2 studies have investigated L2 learners' production of negotiation of meaning. Although these studies have undoubtedly shed light on L2 students' pragmatic knowledge, they are still insufficient to account for their pragmatic competence. Studies about L2 students' performance of discourse phenomena such as how to take turns, how to negotiate meaning, how to use politeness markers, etc. are less frequent. Thus, the researchers were interested in analyzing the use of negotiation of meaning strategies specifically the ones used by Indonesian undergraduate EFL learners.

This present study investigated how non-native speakers (NNSs) of English communicated in English using negotiation of meaning strategies. In particular, it focused on how undergraduate EFL students employed the strategies of negotiation of meaning in English conversations. This study aimed to discuss the Indonesian speakers' applications of negotiation of meaning strategies in English conversations in the pragmatic perspective.

\section{METHODS}

Qualitative research was employed for this study. This current study consisted of verbal data from the participants during their performance. The participants' utilization of negotiation of meaning strategies served as a central phenomenon that the researchers were looking at in this study. The participants of the study were undergraduate students of the English Education Study Program of Sriwijaya University in the academic year of 2013/2014. They were purposefully selected on the basis of their results on a proficiency level test in which they had relatively similar 
level of English proficiency. Six students (three pairs) voluntarily agreed to participate in the research. Pairing system of dyads was employed as they performed a communicative task which prompted the occurrences of negotiation of meaning strategies. As an instrument, an information gap task specifically designed as an instrument to elicit negotiation strategies was performed by the participants in dyads. Information gap activity, spot the difference used in this study required the participants to find similarities and differences between a set of pictures. The data were derived from the language interactions produced by two participants engaged in spot the difference (picture-based comparison). Each pair was assigned 1 conversation task. To collect the data: audio-recording was conducted which was later transcribed for analysis. The data analysis included data coding, data reduction, data display, and drawing conclusion. In coding process, the negotiation strategies were identified and classified referring to those defined by Long (1983a, 1983 b), and Pica \& Doughty (1985) to help the researchers better identify the existence of negotiation of meaning strategies. Negotiation of meaning strategies consist of nine categories: comprehension checks, clarification requests, confirmation checks, word coinage, use of approximation, self-repetition, other repetition, correction, and non-verbal expression of non-understanding. However, for the present study, the researchers only focused on commonly used strategies of meaning negotiation which include comprehension checks, confirmation checks and clarification requests as defined by Long (1983a and b) and Pica \& Doughty (1985). The researchers decided to analyze only these three because there were not many data collected. Using the examples given by the experts, the data were classified based on suitable category.

\section{RESULTS}

Confirmation checks are employed by a listener to ensure whether s/he has heard or understood something the interlocutor said. Confirmation checks are utilized by a listener to verify that he has correctly heard what was previously mentioned by a speaker (Long, 1983a). Rising intonation in comprehension check is a feature that signals the listener to request a confirmation of what the previous speaker has said. Rising intonation indicates that the speaker is requesting confirmation. It can also mean that the interlocutor feels surprised (disbelief) of the previous utterance.

The examples below illustrate this type of strategy.

Example 1:

I: A boy or it's a doll? Because in my picture it's a doll.

B: A doll? I think it's a baby, it has eyes, leg, arms, it has....ears, it has hair. I think it's alive. Yes it's a baby ah...

Confirmation checks occurred 39 times in all three conversations. This type of strategy was the most frequently used by the listeners to establish that the preceding utterance had been heard and understood correctly. The utilization of these strategies are indicated by the use of repetition of all or part of the utterances accompanied by rising intonation.

Repetitions were the second most frequently used strategy in this present study. Mostly repetitions were utilized by the speakers as part of the communication strategy, specifically how to give a clear and comprehensible input to the listeners. Self-repetition is defined as 'speaker's exact or partial repetition of the same lexical item(s) from own preceding utterance, incorporated into a new utterance' (Pica \& Doughty, 1985, p.120). Repetitions were often used by the participants in the case where they speak a bit slowly, making sure that they were saying correctly. In the picture comparison task, the participants repeated their utterance because perhaps they were being careful, making sure that they were saying the right thing as they were looking at the picture. The following example demonstrated this type of strategy.

Example 2:

I: Do you have a cat?

B: Yes, I have one, under ....under the desk, under the TV desk.

Example 3:

B: aaa.. it's a real penguin

I: Plastic doll maybe?

B: No.. no I can see them breathing.

I: It's only a picture

B: It's only a picture. No yes

Although the example above may look like a confirmation check but, it was classified into repetition, other repetition to be precise, because the listener did not use a rising intonation when he uttered it. This repetition strategy was probably employed by the listener to signal his agreement with the previous speaker's utterance "it's only a picture". In this case B was trying to repeat the previous utterance from the first speaker without a rising intonation. Thus, it was not to verify that he has correctly heard what was previously mentioned by a speaker but presumably to agree with the previous statement. Falling intonation can mean that the speaker is requesting agreement.

The third most frequently used strategy is self-correction. Self-correction is "correction by a learner of an error in his or her language use, without assistance from a teacher or other learners" (Richards \& Schmidt, 2010, p. 516).

Example 4

B: I have two penguins here. I don't know how they can live in this room

I: heeee...so it's funny (laugh)

B: eh eh someone should found $(*)$ this picture must be think out of the box, must think out of the box. Ah.. What else do you have? Oh wait wait

In example 4, speaker B corrected his previous utterance by saying 'must think out of the box', without "be". The speaker immediately corrected his utterance after realizing that he 
made error in his previous utterance. This spontaneous ability to self-correct may depend on a speaker's English language proficiency. In this case, the participants have relatively good English as evidenced by their TOEFL score. Therefore, it is expected that they should be able to do self-correction. However, it should be noted that having good English language per se does not prevent language users from making a mistake in communication because sometimes people still make a mistake although they know the correct ones.

In this study, self-repetition seemed to be one of the strategies that speakers employed to negotiate meaning by giving selfcorrection as a way to provide clear and comprehensible message to the listener. However, self-corrections do not always work. In this study, one of the participants was not successful in self-correcting his own error in the following example, speaker B tried to self-correct but he failed to correct it to the correct structure 'a baby boy'.

\section{Example 11}

B: It's a bit complicated. A lot of stuff here, but I can tell you that on this table I have a... a baby, yes a... boy, yes a boy baby

\section{DISCUSSION}

The study found that the participants used confirmation checks, repetitions and self-corrections as negotiation of meaning strategies in performing the information gap task. These three strategies were employed to help the participants expressed their ideas in a more comprehensible way to the interlocutors. This study confirms that negotiation of meaning is important in SLA. It also indicated that that participants were benefited from the process of negotiation for meaning in terms of making comprehensible input to their interlocutors during the interactions. This is in line with what Pica (1987) claims that meaning negotiation can help learners accomplish their language learning by helping them make input comprehensible and modify their own output and by providing opportunities for them to access L2 form and meaning.

The present study revealed that for example, with the use of self-corrections, interlocutors received comprehensible input that ensured their understanding of the utterance. This shows negotiation of meaning facilitates language acquisition. In the same vein, Fuente (2002) argues that negotiation can promote acquisition because it allows learners to understand words and structures beyond their present level of competence and eventually enables them to incorporate them into their L2 production.

This study also revealed that with the utilization of communication strategies such as negotiation strategies, speakers and interlocutors make their communication smooth and effective. Therefore, communication strategies need to be included in the English teaching syllabus to develop learners' communication strategies. Learners should be encouraged to use communication strategies which thus help their own use of the L2 sound more native-like.

One important feature of this study is the use of appropriate task to elicit learners' production of negotiation strategies. The use of communication task in the form of information gap activity employed for this study has generated the occurrences of negotiation meaning. In this particular study, the Spot the Difference activity has promoted negotiation of strategies to emerge during the interaction. This was indicated by the use of certain negotiation strategies with confirmation checks as the most frequently used strategy. The use of Spot the difference activity has stimulated negotiation strategies as the participants interacted and engaged in finding the differences of the pictures. Similarly, Luciana (2005) found that the use of embedded negotiation of meaning promotes students' active involvement when engaged in picture based comparison and picture drawing tasks using negotiation of meaning.

The finding of this study was also supported what has been found by Abdullah (2011) showing that the type of task provided the participants with a greater opportunity for negotiation. The researchers argue that the use of information gap activity (spot the difference) for this study was suitable for the learners' language proficiency as it was comprehensible and did not cause any difficulty for the participants. The expected language produced by this activity was basic language that the learners have already been familiar with. On a similar vein, Jeong's (2011) study revealed that task type affects the quantity of meaning negotiation, and the amount of meaning negotiation is significantly different according to task type.

Another factor that contributed to the amount of negotiation strategies employed by the participants in this study was their language proficiency. Since the students had equally good English proficiency. In this study, it was assumed that the English proficiency had an effect on the amount of the negotiation strategies used. For example, the use of clarification request "I don't understand" was not found in this study. This utterance has something to do with either speaker or interlocutor's language proficiency. If a person has a good mastery of a language, he may not use clarification requests since he has the ability to understand the language well. This was also found in Samani's, et al., (2015) study which revealed that "the proficiency of the participants influences the amount of negotiation for meaning strategies that occur" (p. 16). Another study that also discussed the influence of language proficiency on the use of negotiation strategies is Jeong's study (2011) which also compared the effects of proficiency level on how much negotiation of meaning was produced in the different pairs, and how three different task types affected negotiation. It should be noted that whether a person's language proficiency is good or bad, he or she still negotiates in many different ways in interactions. Bitchener (2004) found that "low proficiency ESL learners do initiate negotiation routines when they 
encounter communication difficulties" (pp. 92-93). The results of the present study showed that even those with good English proficiency still negotiated their meanings with their interlocutors during their interactions.

\section{CONCLUSION}

This study confirms that negotiation of meaning is important in SLA. It also indicated that participants benefited from the process of negotiation for meaning in terms of making comprehensible input to their interlocutors during the interactions. The major findings of the study included the use of confirmation checks, repetitions, and self-corrections as most frequently used negotiations of meaning strategies employed by the participants of this study. The participants employed certain strategies when engaged in an information gap activity, spot the difference activity. The study revealed that they negotiated meaning using the three common strategies to help their interlocutors understand and comprehend meaning. Although it was not clearly known whether those strategies were employed purposefully, the study indicated that the participants used those strategies to help them convey and negotiate meaning. The utilization of certain communication strategies becomes essential because the goal of communication is to have a mutual understanding and effective communication. The strategies employed were believed to make the speaker's meaning comprehensible and therefore conveyed successfully and effectively. Furthermore, this study revealed that the information gap activity provided opportunity for the participants to negotiate meaning especially in spot the difference activity which required them to exchange information and compared the similarities and differences of their pictures. It can be argued that the task has generated the use of certain negotiation of meaning strategies.

\section{REFERENCES}

Abdullah, U. (2011). EIL in practice: Indonesia and Chinese international postgraduate students negotiate meaning. TEFLIN Journal, 22(2),103-117.

Bitchener, J. (2004). The relationship between the negotiation of meaning and language learning: A longitudinal study. Language Awareness, 13(2), 81-95.

Fuente, M. J. (2002). The roles of input and output in the receptive and productive acquisition of words. Studies in Second Language Acquisition, 24(1), 81112.

Jeong, N. (2011). The Effects of Task Type and Group Structure on Meaning Negotiation in Synchronous Computer- Mediated Communication. In Selected Proceedings of the 2009 Second Language Research Forum, ed. Luke Plonsky and Maren Schierloh, 5169. Somerville, MA: Cascadilla Proceedings Project.

Lengluan, N. (2008). An analysis of conversational exchanges between grade 12 Thai sudents and native English speakers via a chat program: Strategies of negotiation for meanings. Bangkok: Graduate School, Srinakharinwirot University.
Long, M. H. (1983a). Native speaker/nonnative speaker conversation and the negotiation of comprehensible input. Applied linguistics 4(2), 126-41.

Long, M. H. (1983b). Linguistic and conversational adjustments to non-native speakers. Studies in second language acquisition, 5(2), 177-193.

Long, M. H. (1996). The role of the linguistic environment in second language acquisition. In W.C. Ritchie \& T.K. Bhatia (Eds.), Handbook of second language acquisition (413-468). San Diego, CA: Academic Press.

Luciana. (2005). Negotiation of meaning in communicative tasks. Indonesian Journal of English Language Teaching, 1 (1), 45-54.

Pica, T. (1987). Second-language acquisition, social interaction, and the classroom. Applied Linguistics, 8(1), 3-21.

Pica, T. (1989). Interlanguage adjustments as an outcome of NS-NNS negotiated interaction. Language Learning, 38(1), 45-73.

Pica, T. (1994). Research on negotiation: What does it reveal about second language learning conditions, processes and outcomes?. Language Learning, 44(3), 493-527.

Pica, T. \& Doughty, C. (1985). Input and interaction in the communicative classroom: A comparison of teacher-fronted and group activities. In S. M. Gass. \& C. G. Madden (Eds.), Input in second language acquisition (115-136). Rowley: Newbury House.

Pica, T., R., Young., \& Doughty, C. (1987). The impact of interaction on comprehension. TESOL Quarterly, 21(4), 737-758. 